\title{
Crimes e segredos na violência sexual contra as mulheres: o diálogo entre Durkheim e Simmel
}

\author{
Alba Jean Batista Viana' \\ Eduardo Sérgio Soares Sousa ${ }^{2}$
}

\section{Resumo}

Este estudo objetiva refletir acerca dos crimes e dos segredos que envolvem a violência sexual contra as mulheres. Trata-se de uma revisão bibliográfica sobre vivências femininas, considerando que a não publicização do ato violento aparece como uma preocupação constante entre as mulheres. A partir do arcabouço teórico proposto por Émile Durkheim e Georg Simmel, verificou-se que esta violência está imersa em uma trama social, seja existencial ou da ordem das hierarquias de gênero. Na concepção de crime apresentada por Durkheim, pode-se compreender que a mudança de valores, por atingir os estados da consciência coletiva, é central para que a violência contra a mulher possa ser vista como um "ato criminoso". A partir de Simmel, o segredo, enquanto categoria sociológica, não deve ser interpretado como omissão ou inércia, mas como uma forma de manutenção dos laços sociais. As interações dos indivíduos ampliam as possibilidades do mundo social.

Palavras-chave: Violência sexual. Violência de gênero. Violência contra as mulheres. Crime. Segredo.

\section{Introdução}

Na literatura, os estudos dos crimes de violência sexual contra as mulheres têm suas origens no início da década de 1980. Entre os trabalhos que compuseram o universo dessas análises, reconhecemos três correntes teóricas assim designadas: dominação masculina, dominação patriarcal e, relativizando,

I Mestre em Ciências da Nutrição pela Universidade Federal da Paraiba. Brasil e doutoranda no Programa de Pós-Graduação em Sociologia da Universidade Federal da Paraiba/UFPB. E-mail: albajean2009@gmail.com.

2 Doutor em Sociologia pela Universidade Federal da Paraíba/UFPB e professor no Programa de Pós-Graduação em Sociologia nessa instituição.

E-mail: esegiosousa@uol.com.br. 
dominação-vitimização. Tais estudos têm como propósito compartilhar referências teóricas de modo a compreender e definir o fenômeno social da violência contra as mulheres e a posição das mulheres em relação à violência (SANTOS; IZUMINO, 2005).

A corrente da dominação masculina é constituída pelas manifestaçóes das relaçôes de poder historicamente desiguais, estabelecidas entre homens e mulheres, propiciando a violaçáo dos direitos humanos. Nesta perspectiva, tem-se uma violência oriunda da ideologia, da supremacia do masculino sobre o feminino, arraigada em uma sociedade que perpetua uma situação de inferioridade da mulher como um atributo natural e, portanto, inerente a um papel social a ser desempenhado. Nesse contexto social, a mulher em situação de violência é compreendida tanto como vítima quanto cúmplice da dominação masculina. De acordo com Chauí (1985, p. 43), esse tipo de manifestação "[...] se trata de um discurso que não só fala de 'fora' sobre as mulheres, mas, sobretudo, [...] se trata de uma fala cuja condição de possibilidade é o silêncio das mulheres $[. .]$.$" .$

Na concepção de Gregori (1993a), os pressupostos adotados na análise de Chauí transformam diferenças em relaçóes hierárquicas de dominaçáo, nas quais se desconsidera que as mulheres nas relaçóes familiares, mesmo em situaçáo de subalternidade, podem agir, condenar, ordenar e, por vezes, agredir. Por conseguinte, Gregori acredita que Chauí (1985), ao considerar tais manifestaçóes como mera reação ou reprodução, pode "cair na armadilha" de, mais do que estimular uma transformação, propiciar a conservação de uma estrutura favorável à violência. Com relaçáo a esse aspecto, o entendimento de Chauí é de que as mulheres podem até perpetrar atos de violência, todavia, tais expressóes náo ocorrem a partir de "escolha" ou "vontade" própria, tendo em vista que a subjetividade feminina é privada de autonomia.

A segunda corrente - dominaçáo patriarcal - foi introduzida no Brasil pela socióloga Heleieth Saffioti e apresenta uma abordagem que filia a dominação masculina aos sistemas capitalista e racista (SANTOS; IZUMINO, 2005). Essa conformação teórica, por sua vez, compreende a violência como expressáo do patriarcado, atribuindo a este sistema uma ideologia machista, a qual socializa o homem para dominar a mulher e esta para sujeitar-se ao seu poder - "o poder do macho" (SAFFIOTI, 1987). No entanto, diferentemente de Chauí (1985), Saffioti (2011) recusa juízos que coloquem as mulheres em 
posição de cúmplices da violência, por considerar que estas, ainda que na condição de vítimas e tratadas como "não sujeito" em uma relação desigual de poder em relação aos homens, constituem-se efetivamente como sujeitos de seus relacionamentos. Contudo, a autora acredita que uma mulher se submete à situação de violência não por concordar, mas por não usufruir no meio social de um poder semelhante ao do homem. Logo, diante de tais condiçóes, as mulheres cedem, uma vez que têm poder suficiente para consentir.

Soares (2012), em suas reflexóes sobre o assunto, considera que, embora parte da violência de gênero revele a manifestação do desejo masculino de controlar e dominar a mulher, é preciso atentar para a complexidade das interaçóes existentes nessas relaçóes. Até porque, quando se trata dessa modalidade de violência, as experiências são distintas "[...] tanto na forma, na intensidade e na frequência, quanto nos contextos, nos significados e nos impactos que produzem" (SOARES, 2012, p. 192). Nesse sentido, Gregori (1993b) e Grossi (1994) reputam, como condição essencial, buscar entender a violência de gênero como algo relacional, em que homem e mulher devem ser situados socialmente como sujeito da relação. Sob esse aspecto, Soares (2012, p. 193) ressalta que as vantagens do mundo masculino podem ser palpáveis e difusas; todavia, "[...] o desejo de controlar e de dominar não é um atributo exclusivo dos homens [...]". De modo que o modelo patriarcal pode abranger variados tipos e subtipos de dominação exercidos pelas mulheres.

A respeito dessa abordagem, temos, como exemplo, a assistência prestada pelas Delegacias de Defesa da Mulher, criadas com o intuito de combater a violência contra as mulheres e nas quais se previa um espaço institucional onde o acolhimento aos agentes femininos seria realizado por profissionais do mesmo gênero. Com isso, esperava-se favorecer as denúncias, os encaminhamentos das queixas e o relacionamento entre policiais e vítimas. No entanto, no cotidiano, observa-se uma falta de afinidade entre as vítimas de violência e as policiais, uma vez que estas, no transcurso do exercício profissional, reproduzem um comportamento análogo ao masculino; assim, as ocorrências de violência são descaracterizadas (IZUMINO, 2015).

A terceira corrente dos estudos sobre a violência contra a mulher introduz, no debate, uma ênfase bastante distinta das duas anteriormente apresentadas, por recorrer a uma perspectiva voltada para a relativização da dominação-vitimização. Nessa categoria de análise, o trabalho de Maria Filomena Gregori 
se destaca como um dos mais relevantes no âmbito das discursóes feministas a respeito do assunto.

Pensando, pois, em termos do binômio dominação-vitimização, Gregori rejeita a adoção de papéis dualistas e fixos para as relaçóes de gênero - em que os homens são pré-concebidos como algozes e as mulheres como vítimas, por acreditar que essa construção dual inviabiliza mudanças no exercício dos papéis sociais da mulher em situação de violência (GREGORI, 1993a). Corroborando esse ponto de vista, Soares (2012, p. 191) afirma que “[...] aprisionar os indivíduos em categorias rígidas, como vítimas e agressores, [...] acaba por torná-los refratários a mudanças de autopercepção, de percepção do outro e, portanto, de comportamento". Ademais, Gregori percebe a violência "como uma forma de comunicação e um jogo do qual a mulher não é 'vítima' senão 'cumplice"” (SANTOS; IZUMINO, 2005, p. 2). Logo, a adoção de discursos de apologia da vitimizaçáo feminina como resultado do exercício da dominação masculina, restringe as análises do fenômeno e de seus significados em virtude de este exibir uma dinâmica interna própria. Além do mais, as mulheres vivem e se relacionam de formas diferentes, de modo que a identidade delas se encerra nas trajetórias e nas relaçôes vivenciadas (GREGORI, 1993b).

Machado (2010), apoiando-se nessa perspectiva, adverte sobre a necessidade de se tentar compreender a violência contra a mulher a partir da desconstruçáo de concepçóes que remetam a sentidos e a sentimentos unitários e de significação única, por acreditar tratar-se de uma modalidade subversiva e não fechada, que comporta olhares voltados para as diferentes posiçóes dos sujeitos. Sob esse aspecto, Gregori (1993b) argumenta que:

É preciso, também, ter cautela em não interpretar como se fosse a verdade única dos fatos as descrições ou representações das mulheres sobre suas relações com o mundo. Reter suas visões, noções e versões é importante porque revela a maneira pela qual elas classificam e interpretam o mundo. Mas são "construções" parciais: apenas descrevem um dos lados de que se constituem as relações de poder entre os sexos [...]. É preciso investigar o "lado" dos homens, não tomando o masculino como dado, mas também como uma identidade que se constitui na trajetória, na vivência. (MACHADO, 20I0, p. 200).

Os argumentos presentes nos pressupostos de Gregori (1993a, 1993b) não desconsideraram os sentimentos investidos pelas mulheres nas relações desiguais de gênero, mas propóem reflexôes que possibilitem uma nova 
abordagem sem determinar uma dicotomia opositora e fixa nos papéis de gênero. Portanto, para Machado (2010), faz-se imprescindível relativizar essa representaçáo social de dominação masculina e vitimização feminina para que se avalie em profundidade o contexto das ocorrências da violência contra as mulheres.

Atualmente, a violência contra a mulher é reconhecida como um tema de preocupaçáo internacional; contudo, nem sempre foi motivo de discussóes relevantes para as sociedades. Essa recente percepção e consciência são frutos de um trabalho incansável e articulado de diversos grupos e movimentos sociais, especialmente dos movimentos de mulheres e os feministas. Esses fenômenos sociais possibilitaram a mobilizaçáo de forças decisivas no sentido náo apenas de dar visibilidade à violência, mas, também, de impulsionar políticas públicas específicas, que resultaram na criação de serviços de assistência às mulheres em situação de violência sexual, bem como configurar instrumentos jurídicos capazes de promover e tutelar os direitos das mulheres e de sancionar os violadores desses direitos, principalmente no âmbito das relaçóes domésticas e familiares (SARTI; BARBOSA; SUAREZ, 2006; LIMA; BÜCHELE; CLÍMACO, 2008).

Apesar da luta pelo reconhecimento social e legal dos direitos femininos, os casos de violência sexual não deixaram de acontecer, nem passaram a ser vistos de maneira uniforme, pela sociedade, como um crime ${ }^{3}$. Esta naturalização, por si só, já indica a persistência de um modelo masculino dominante na vida cotidiana (BOURDIEU, 2010). Por isso, no contexto da sociedade atual, a violência encontra-se entre os assuntos de maior relevância social, representando um dos mais graves problemas sociais.

O presente estudo atenta, por meio de uma reflexáo teórica, para as categorias crime e segredo, que envolvem a violência sexual contra as mulheres. Trata-se de explorar as sociologias de Émile Durkheim e Georg Simmel, buscando trazer à luz certos elementos da vida social das mulheres em contexto de pós-violência.

\section{Contexto e metodologia do estudo}

Este trabalho é resultado de uma revisão bibliográfica sobre a violência sexual contra as mulheres, em que a não publicização do ato violento

3 Embora legalmente seja crime, conforme a Lei $n^{\circ}$ II.340 (BRASIL, 2006), popularmente conhecida como Lei Maria da Penha, e a Lei no 12.015 (BRASIL, 2009). 
aparece como uma preocupação constante no universo feminino. A partir dessa evidência, buscamos compreender, pela via das reflexões teóricas de Émile Durkheim e Georg Simmel, a dinâmica entre crime e segredo que vem sendo acionado pelas mulheres a partir da violência sexual.

Em termos de uma revisão bibliográfica, facilmente encontram-se estudos que demonstram como a violência sexual é considerada social e juridicamente um crime. A questão sociológica a ser pensada refere-se à sua naturalização e à convivência pós-violência. Desta forma, desconstruir tal "naturalização" apresenta-se como uma exigência para o pensamento reflexivo. É, no entanto, sobre os arranjos privados e públicos, utilizados pelas mulheres para manter-se após a violência, que encontramos o segredo como possibilidade de sociabilidade. Por isso, nosso objetivo compreende refletir sobre a violência sexual em sua dupla perspectiva: crime e segredo, trazendo à tona a sua criminalização e o silêncio como partes do rearranjo social pós-violência.

A revisão bibliográfica foi realizada no período de janeiro a março de 2013, utilizando como referencial teórico livros, artigos publicados nos periódicos científicos brasileiros, principalmente os pertencentes à coleção disponibilizada na Scientific Electronic Library Online (SCIELO), entre outros. Os estudos foram selecionados a partir da referência aos seguintes descritores: violência sexual, violência de gênero, violência contra a mulher, e atenção à saúde das mulheres vítimas de violência. Consideraram-se os artigos disponibilizados no idioma português.

Após as análises e interpretações, foi possível realizar uma aproximação crítica com os teóricos e construir a síntese integradora que é apresentada a seguir, dividida em duas categorias temáticas: crimes e segredos.

\section{As faces da violência sexual: crimes e segredos}

\section{I. Crimes}

Tendo em vista que os direitos das mulheres são parte dos direitos humanos e como tais devem ser respeitados e garantidos, a violência sexual praticada contra as mulheres é considerada uma violação de direitos e um crime. De acordo com a Lei no 12.015/2009, este tipo de agressáo corresponde aos crimes contra a dignidade sexual, que se relacionam aos estupros, violação 
sexual mediante fraude, assédio sexual, estupro de vulnerável, corrupção de menores, satisfação da lascívia mediante presença de criança ou adolescente e favorecimento à prostituição.

Nos casos dos crimes sexuais, existe uma série de fatores que acabam diferenciando-os dos demais e permitindo que, muitas vezes, eles percam a força de um crime para o senso comum. Essa forma distorcida de encarar a violência sexual é bastante habitual na nossa sociedade, de modo que, em muitos casos, a própria mulher torna-se incapaz de reconhecer-se como vítima do crime.

A demonstração da permanência do crime em todas as sociedades constituiu o fator determinante na integração do pensamento sociológico de Durkheim, que trouxe pontos de reflexáo para a sociologia criminal, tendo em vista que ele não atribuía aos crimes um caráter patológico, mas os classificava como fatos sociais e de carácter normal, dado o fato de que aparecem como estreitamente ligados às condiçóes de qualquer vida coletiva. Nas palavras de Durkheim (2001, p. 83), “[...] classificar o crime entre os fenômenos de sociologia normal, não só dizer que é um fenômeno inevitável, ainda que lastimável, [...] é afirmar que é [...] uma parte integrante de qualquer sociedade sâ”.

$\mathrm{Na}$ concepção durkheimiana, o crime é parte da natureza humana, persiste em todas as épocas e em todas as classes sociais. Ele é considerado normal porque não há nenhuma sociedade na qual o comportamento criminoso esteja ausente, ou seja, para Durkheim, não existe sociedade sem atos criminosos, o que existe são modificaçóes na forma da criminalidade, diferenciando-se de um período para outro. De modo que, sempre e em todos os grupos de indivíduos, haverá açóes qualificadas como crime, porque sempre existirão ações que irão ferir os sentimentos coletivos (DURKHEIM, 2001).

Por meio de sua teoria, Durkheim procura provar que os fatos sociais independem daquilo que pensa ou faz cada indivíduo em particular. Pois, embora os indivíduos possuam seus valores, gostos, formas particulares de agir e sentir as coisas - que Durkheim conceitua como consciência individual -, existe, implicitamente, no interior de cada grupo, um comportamento padronizado, que náo depende de sua conduta e de seu pensamento. Essa consciência individual está subordinada a um conjunto de normas, regras e sançóes que sobrevivem ao longo das geraçóes e que são impostas aos indivíduos sobrepondo-se à consciência individual. E este conjunto Durkheim denomina de consciência coletiva (TESKE, 2005). 
A consciência coletiva representa a organização social porque é objetiva, não vem de uma só pessoa ou grupo, mas encontra-se espalhada por toda a sociedade; por isso, ela é exterior ao indivíduo. De acordo com Durkheim (1999, p. 50), "[...] a consciência coletiva é toda a consciência social”. Nesse sentido, a sociedade age sobre o indivíduo de forma coercitiva, de modo a exercer uma autoridade sobre a maneira como o indivíduo deve agir no seu meio social.

Para Durkheim, a existência de uma sociedade, bem como da própria coesáo social, só é possível a partir de um determinado grau de consenso entre os indivíduos, que ele designa de solidariedade, a qual varia conforme o modelo de organização social. A coesão social depende de que os membros da sociedade partilhem as regras morais que lhes imprimem o valor e o primado da coletividade, conformando e padronizando suas concepçóes e condutas. Assim, na ótica durkheimiana, a solidariedade social é vista como um fenômeno totalmente moral, uma vez que "[...] nós pensamos e agimos moralmente de forma moldada pela sociedade" (MASSELLA et al., 2009, p. 26).

Dessa forma, a vida em sociedade prevê a existência de processos de interação social estabelecidos sob a forma de regras e normas que funcionam para impedir que os indivíduos cometam atos que acarretem prejuízos para a organizaçáo social e para eles próprios. Nesse sentido, o direito, por meio de suas normas, representa uma parte dos mecanismos encontrados pela sociedade para obter o controle social sobre as condutas individuais (BARREIRA; BATISTA, 2011).

A concepção de Durkheim é de que aqueles que ameaçam ou abalam a unidade do corpo social devem ser punidos para que a coesáo seja protegida. A pena náo serve, apenas, para corrigir o culpado ou para intimidar seus possíveis imitadores, ela tem, principalmente, a função de proteger a sociedade, a fim de sustentar a vitalidade dos laços que ligam os membros entre si, evitando que eles afrouxem e se debilitem (DURKHEIM, 1999).

Com base no pensamento de Durkheim, pode-se considerar que o crime de violência sexual contra a mulher é um fato social tido como normal, visto que, em todas as sociedades e em todas as épocas, ele participa das relaçóes sociais e tem a função de promover a solidariedade entre os indivíduos, fazendo com que solidariedade e moral se imponham sobre as tendências egoístas (STUKER, 2015). A partir da década de 1980, a luta pela proteção dos direitos 
humanos e dos direitos das mulheres contribuiu para que o crime de violência sexual contra a mulher se deslocasse do espaço privado para o público e passasse a produzir reaçóes de repúdio, bem como expectativas de que essas práticas de violência deixassem de fazer parte das estatísticas institucionais e de que fossem reconhecidos os direitos das mulheres (TEIXEIRA, 2009). Por conseguinte, tais mudanças propiciaram a exibição de um modo mais ostensivo de solidariedade por parte da sociedade.

Nesse sentido, pode-se afirmar que a filiação de políticas públicas à perspectiva de gênero e as aquisiçóes obtidas nesse âmbito, a exemplo da criação das delegacias das mulheres em 1985, do desenvolvimento da norma técnica para prevençáo e tratamento de agravos resultantes da violência sexual contra as mulheres e adolescentes, adotada pelo Ministério da Saúde em 1998, a promulgaçáo da Lei Maria da Penha (Lei no 11.340) em 2006 e da nova Lei do Crime de Estupro (Lei no 12.015) em 2009, o que modifica a redação de alguns crimes sexuais previstos no Código Penal Brasileiro (BRASIL, 1940), dentre outras, demonstram, de acordo com Bandeira e Almeida (2013), que a sociedade, nas últimas décadas, tem vivenciado um intenso processo de mudanças, e ela não se apresenta indiferente a tais questóes. Ademais, é importante reconhecer que os efeitos provenientes de outros fatores, como o papel do Estado em face da globalização; "[...] os desafios colocados pela diversidade étnico-racial; as alteraçóes [...] nos arranjos familiares; as mudanças no tradicional padrão da divisão sexual do trabalho e nos padróes da sexualidade, dentre outros" (BANDEIRA; ALMEIDA, 2013, p. 44) contribuíram para esse processo de transformaçáo. Posto isso, é preciso ressaltar que, apesar dos problemas existentes na efetivação dessas políticas, tais açóes são oriundas da solidariedade apregoada por Durkheim, já que elas procedem da oposição dos movimentos sociais às assimetrias de gênero e à banalizaçáo dos crimes cometidos contra a mulher.

Durkheim (1999) entende que é por meio do sistema jurídico que podemos reconhecer o modelo de organizaçáo de uma determinada sociedade e, consequentemente, os tipos de solidariedade existentes que favorecem a coesáo social. Nesse sentido, para o autor, o ato criminoso cometido náo exprime a propriedade essencial do crime, mas uma de suas repercussóes, de modo que "[...] náo se deve dizer que um ato criminoso ofende a consciência comum por ser criminoso, mas é criminoso porque ofende a consciência coletiva. [...] 
Não o reprovamos por ser um crime, mas é um crime porque o reprovamos" (DURKHEIM, 1999, p. 51-52). Um ato é considerado como nocivo por ser rejeitado pela sociedade. O que vingamos, o que o criminoso expia, é o ultraje moral. Todos os atos que atingem a consciência coletiva não são perigosos por si mesmos, mas sim porque, ao abalá-la, afetam igualmente a coesão social e comprometem a sociedade. A mudança de valores, desta forma, é central para que a violência contra a mulher possa ser vista como um "ato criminoso" passível de punição pela sociedade por ferir os estados da consciência coletiva (DURKHEIM, 1999, p. 51-52).

\subsection{Segredos}

A violência sexual produz uma cisáo entre a intencionalidade e a corporeidade. A subjugação da mulher a um corpo instrumento determina a ruptura de uma harmonia na sexualidade que pode desenvolver uma conotação moral negativa. Neste tipo de violência, o corpo é um simples instrumento, cortando-se a relaçáo com a pessoa encarnada no corpo, uma vez que a agressão nega a intencionalidade do outro, reduzindo-o a um corpo-instrumento exclusivo da excitação e do prazer sexual (MARZANO-PARISOLI, 2004).

A violência nega a autonomia à parte da relação submetida, nega-lhe a possibilidade de ser sujeito, de construir-se e constituir-se como capaz de autonomia na relação. A violência apresenta-se como a ação que trata um ser humano não como sujeito, mas como coisa; as relações de força materializam a violência porque coisificam pessoas, indivíduos. Esse conceito, quando aplicado às relações sociais entre os sexos, significa dizer que são violentas porque tornam diferentes em desiguais, determinando uma relação assimétrica e hierárquica. (CHAUÍ, 1985, p. 26).

As mulheres, ao vivenciarem situaçóes de violência sexual, atribuem a essas situaçóes significados indesejados que interferem na expressáo do seu corpo, ou seja, na sua corporeidade. Dessa forma, os efeitos e as reaçóes produzidas pela agressão são distintos e dependem das singularidades de cada indivíduo, de sua bagagem cultural e histórica armazenadas em seu corpo, bem como, de suas experiências (LABRONICI; FEGADOLI; CORREA, 2010).

As vítimas de violência sexual sofrem com o preconceito. Ideias estereotipadas são concebidas e mitos são construídos a seu respeito. $\mathrm{O}$ sofrimento das mulheres vem acompanhado de uma variedade de sentimentos, emoçóes, e da necessidade de náo compartilharem a experiência vivenciada, o que 
intensifica a emoção reprimida e dificulta uma elaboração dos sentimentos e dos acontecimentos. Pois, para elas, é vergonhoso falar dos fatos e do problema, assim como expor a experiência vivida para outras pessoas. Essas mulheres não só se recusam a falar sobre o assunto, como também a estar em situaçóes que lembrem a violência, e isto traz como consequência o isolamento delas em relação a outras mulheres, e mesmo em relação à família, bem como o isolamento dos núcleos familiares em relação à família extensa e à vizinhança (COSTA et al., 2007).

Dentre as particularidades que acompanham as mulheres em situação de violência sexual, a vergonha destaca-se como um dos problemas de grande relevância, tendo em vista que afeta aspectos da autoidentidade e que tende a abalar elementos do comportamento e os modos de retribuiçáo que eles sugerem ou implicam. A vergonha atinge diretamente a autoidentidade, "[...] porque é essencialmente a ansiedade sobre a adequação da narrativa por meio da qual o indivíduo sustenta uma biografia coerente" (GIDDENS, 2002, p. 65). Assim, na situação de violência sexual, a vergonha se manifesta como um fenômeno essencialmente visível e de ordem pública. "Esta perda de um sentido de si estável é chamada, algumas vezes, de deslocamento ou descentração do sujeito" (HALL, 2007, p. 9). Tal condição leva ao desenvolvimento de uma crise de identidade, pois "[...] a identidade somente se torna uma questáo quando está em crise, quando algo que se supôe como fixo, coerente e estável é deslocado pela experiência da dúvida e incerteza" (HALL, 2007, p. 9).

Estudos revelam que a vergonha das mulheres com relação à violência sofrida também tem sido identificada como um dos fatores de empecilho à busca de suporte no sistema de apoio familiar e comunitário, o que muitas vezes dificulta o rompimento com a situação abusiva (NARVAZ; KOLLER, 2006).

Nessa condição, a manifestação do sofrimento encontra-se afiliada à violência e também aos constrangimentos provocados por ela, principalmente "[...] porque a violência se constitui em avesso da possibilidade de comunicação" (SARTI, 2011, p. 5). A violência pode ser concebida como algo que ultrapassa o que é próprio das relaçóes conflituosas; ela constitui o limite do que não pode ser relacionado e/ou comunicado (WIEVIORKA, 2004).

É difícil estimar a magnitude da violência sexual contra as mulheres, pois as vítimas tendem a silenciar sobre o assunto. Nessas circunstâncias, a construção do silêncio que envolve as vítimas e seus familiares propicia o 
desencadeamento de uma complexa dinâmica em que uma variedade de fatores se mantêm interligados, dentre eles destaca-se a síndrome do segredo, cuja dissolução é uma tarefa difícil, uma vez que demanda aproximaçôes e afastamentos entre os familiares, tendo em vista que o imaginário social emergiu, colocando a mulher em situação de violência sexual como uma figura indolente, perpassada pelo gene da impureza social, carregando consigo a transgressão da ordem social (MASON, 2002; CARVALHO, 2011).

Na concepção de Simmel (2011), o segredo envolve toda uma dinâmica comunicativa, feita de retóricas, de transparência, de opacidade, de cooperação, de confiança e também de certos modos de revelação. Sem esses elementos seria difícil viabilizar as relaçóes sociais. Tais elementos, expressos como atitudes, são produtos e objetos de processos educativos pelos quais a sociedade se reproduz, estando imbricados na ética e na moralidade social.

O segredo desempenha um modo de ritualizar as relações colocando o dito e o não dito como meio de configurar o público e o privado. Do ponto de vista do estigma, este atua de forma a delinear o que pode ser desvendado e o que deve ser manifesto para a manutenção dos laços sociais. (CARVALHO, 20II, p. 4).

O segredo faz parte da dialética social, considerando que a sociedade se apresenta com uma tendência para se revelar e, ao mesmo tempo, para se esconder. Nesse sentido, o segredo surge como ação de dissimular as realidades através de meios negativos e positivos, possibilitando o alargamento da vida social, porque impede muitos conteúdos existenciais de se manifestarem (LEANDRO; LEANDRO; NOGUEIRA, 2011).

Dessa forma, o segredo pode diferenciar-se mediante duas singularidades: o escondido e o mascarado. $\mathrm{O}$ escondido refere-se à ordem do náo dito, daí a importância do silêncio, enquanto o mascarado, por sua vez, faz parte do domínio da mentira, que constitui uma forma social de adaptar o segredo e a dissimulaçáo. $\mathrm{Na}$ visão de Simmel, o segredo oferece "[...] a possibilidade de um segundo mundo junto com o mundo manifesto, sendo este decisivamente influenciado por aquele" (SIMMEL, 2011, p. 99).

Esse segundo mundo cria relaçóes entre os detentores do segredo e produz, também, comportamentos próprios, de modo que as relaçôes estabelecidas poderão ocorrer justamente por haver algo que os une, que os mantêm envolvidos através de uma cola social que os distingue e denuncia mutuamente (KOPP, 
2005). O segredo, enquanto meio de comunicação, perpassa a ocultação e a revelação.

O controle das maneiras de ação e comunicação do sujeito está voltado para a proteçáo da identidade social frente à ordem social vigente. É por isso que o segredo envolve algumas dimensóes das interaçóes sociais, tais como a confiança e a ocultação (CARVALHO, 2011).

Simmel também situa o segredo como um conjunto de relações intrinsecamente ligado à sua contrapartida, à revelação, que pode assumir a forma de traição e cuja expressão é sempre muito complexa e significativa para a sociedade e para cultura. Do ponto de vista sociológico, a importância e as tonalidades culturais que o binômio ocultação/revelação assume em cada configuração histórica local superam a valoração moral que delas se possa fazer. Sociologicamente, mais do que um conteúdo, um objeto unicamente de ocultação que uma vez revelado se esvaziasse e perdesse o sentido [...]. (MALDONADO, 20 I I, p. 98).

Posto isso, as particularidades do segredo envolvem as combinaçóes revelação e ocultação. A revelação do segredo na vida do indivíduo representa o conhecimento de outrem. Nessa perspectiva, "[...] o segredo contém uma tensão que se dissolve no momento da revelação. Este momento constitui o apogeu no desenvolvimento do segredo" (SIMMEL, 2011, p. 103). Assim, o segredo, ao mesmo tempo em que desenvolve barreiras entre os indivíduos, proporciona o desafio de rompê-lo.

Todavia, na existência do segredo, a intencionalidade da ocultaçáo assume uma intensidade muito maior no embate com a revelação. Tal situação dá lugar ao mascaramento de fatos ou acontecimentos.

Essa ocultação acaba por criar uma relação diferenciada com aquele que não comunga dos mesmos conhecimentos. O desconhecedor pode passar a desejar saber o que é ocultado, a acreditar que deva saber por direito ou respeito. A interação humana é ditada, nesses casos, pela existência do segredo, pelo esforço de mantê-lo, pela tentativa de romper e pelo desejo de fazer parte. (KOPP, 2005, p. 3).

Na concepção de Simmel (2011, p. 102-103), o segredo situa a pessoa em uma

[...] posição de exceção; opera como uma atração pura e socialmente determinada [...]. A partir do segredo que sombreia tudo o que há de significativo e profundo, origina-se a falácia de que tudo o que for misterioso será importante e essencial. Diante do desconhecido, o impulso natural do homem a idealizar e o seu temor natural cooperam para com o mesmo 
objetivo: intensificar o desconhecido através da imaginação e dar-lhe uma ênfase que nem sempre corresponde à realidade patente.

No âmbito da violência sexual contra a mulher, o segredo destaca-se como uma forma de pensar e agir fundamentada na manutenção dos laços sociais. $\mathrm{Na}$ perspectiva simmeliana, o segredo enquanto categoria sociológica estabelece-se como uma construçáo social baseada nas interaçóes dos indivíduos que ampliam as possibilidades do mundo social. De modo que o medo da exposição e da traição, que gera individualismo, também determina novas formas de sociabilidade, onde emergem novas maneiras de agir e sentimentos como a lealdade e a confiança, fazendo surgir um modo de socialização e outra forma de integração dos laços sociais. Assim, dessa apreensão entre revelação e ocultação, surgem às diversas formas de arranjos sociais que expressam os relacionamentos permeados pelo segredo (CAMPOS, 2008; CARVALHO, 2011).

Neste cenário, muitos são os mecanismos existentes na sociedade que inviabilizam o rompimento da ocultaçáo do segredo, tais como vergonha, diminuição da autoestima, estigma, ausência de procedimentos democráticos e o descrédito nos serviços de apoio às mulheres em situaçáo de violência sexual - em especial, nos serviços de segurança pública, visto que os policiais não acreditam na veracidade das histórias das vítimas -, dos sentimentos de impotência; além disso, as manifestaçóes emocionais apresentadas por essas mulheres são compreendidas como sintomas de patologias. Também perdura o mito de que somente mulheres promíscuas são violentadas e, dessa forma, a violência encontra justificativa na "conduta imoral" dessas mulheres (PERENTE; NASCIMENTO; VIEIRA, 2009).

\section{Considerações Finais}

A violência sexual contra as mulheres provém das relaçóes de poder e da dominação exercida pelos homens, advindas das construçôes sociais interiorizadas que privilegiam o masculino. Acrescenta-se a este ponto a necessidade da reflexáo sobre o dualismo e a vitimizaçáo empregados para visibilizar esse fenômeno; pois, se por um lado, publiciza a violência, por outro, reforça a falsa ideia da incapacidade de essas mulheres reagirem.

A relação social assimétrica entre os sexos explica a agressão contra a mulher, já que esta não se enquadra no padrão considerado superior. Na visão de 
Durkheim, a sociedade é uma autoridade moral dotada de uma consciência coletiva. É essa a obrigação moral que liga o indivíduo à sociedade por meio de suas normas e seus mecanismos de controle. Com isso, espera-se que nenhum indivíduo venha a transgredir os valores sociais. Os atores desviantes são, portanto, os não socializados, ou seja, aqueles que não internalizaram a moral preponderante.

O criminoso é aquele que rompe o contrato social, sendo por isso uma ameaça à continuidade da coletividade. Dessa forma, é necessário punir o infrator como exemplo aos demais, de maneira que todos venham a seguir as regras e a lei. A lei simboliza a solidariedade social na medida em que positiva os valores que unem os indivíduos. O processamento do crime pelo sistema de justiça criminal, por sua vez, representa as operaçóes do sistema de solidariedade necessárias para perpetuar a sociedade.

Durkheim entende que, na conjuntura do crime, o que se pune náo é o indivíduo, mas a violaçáo que ele realizou nos sentimentos e valores instituídos no seio social. Nesse sentido, o crime é uma conduta que nega o caráter coletivo dos sentimentos; por isso, quem deve punir o criminoso é a coletividade, já que apenas ela pode sentir a dor e os prejuízos da ação criminosa.

Pensando a partir de Simmel (2011), na situação de violência sexual a humilhação e a vergonha sentidas pelas mulheres sobrepóem-se ao sentimento de justiça e, daí, o segredo não deve ser interpretado como omissão ou inércia. O segredo, enquanto categoria sociológica, consiste em uma forma de manutenção dos laços sociais e estabelece-se como uma construção social baseada nas interaçôes dos indivíduos que ampliam as possibilidades do mundo social, e cujos conteúdos não podem ser levados à publicidade. No entendimento de Simmel (2011), o segredo nas relaçóes sociais não atua apenas como um simples ato de ocultação, mas realiza categorizaçóes simbólicas e sociais que requerem formas de agir e pensar articuladas com o cotidiano.

Na perspectiva desta reflexão, o ponto mais importante é o caráter relacional do binômio crime/segredo, nos pensamentos de Durkheim e Simmel, como elementos constituintes das relaçóes de violência sexual contra as mulheres. 


\section{Referências}

BANDEIRA, L. M.; ALMEIDA, T. M. C. de. A transversalidade de gênero nas políticas públicas. Revista do Ceam, Brasília, v. 2, n. 1, p. 35-46, jan./jun. 2013. Disponível em: <http://periodicos. unb.br/index.php/revistadoceam/article/view/9735>. Acesso em: 30 jan. 2015.

BARREIRA, C.; BATISTA, É. (In)Segurança e Sociedade: treze liçôes. São Paulo: Pontes Editores, 2011. BOURDIEU, P. A dominaçáo masculina. 7. ed. Tradução de Maria Helena Kühner. Rio de Janeiro: Bertrand Brasil, 2010.

BRASIL. Decreto-Lei no 2.848, de 7 de dezembro de 1940. Código Penal. Diário Oficial da Uniáo, Brasília, DF, 31 dez. 1940. Disponível em:<http://www.planalto.gov.br/ccivil_03/decreto-lei/del2848. htm>. Acesso em: 28 jan. 2015.

BRASIL. Lei ${ }^{\circ} 11.340$, de 7 de agosto de 2006. Disponível em: < http://www.planalto.gov.br/ ccivil_03/_ato2004-2006/2006/lei/l11340.htm>. Acesso em: 9 abr. 2015.

BRASIL. Lei n ${ }^{\circ} 12.015$, de 7 de agosto de 2009. Disponível em: < http://www.planalto.gov.br/ ccivil_03/_ato2007-2010/2009/lei/l12015.htm>. Acesso em: 9 abr. 2015.

CAMPOS, R. B. C. Sociabilidade, Medo e Estigma no contexto urbano contemporâneo: o bairro do Roger na cidade de João Pessoa - PB. 2008. Trabalho de Conclusão de Curso (Graduação em Ciências Sociais) - Universidade Federal da Paraíba, 2008.

CARVALHO, Á. A. de. Reflexôes acerca das representaçôes sociais em Durkheim e o estudo da AIDS. Caos, Revista Eletrônica de Ciências Sociais, Paraíba, n. 18, p. 4-14, set. 2011.

CHAUÍ, M. Participando do debate sobre mulher e violência. In: CHAUÍ, M. et al. (Orgs.). Perspectivas antropológicas da Mulher: sobre mulher e violência, vol. 4. Rio de Janeiro: Zahar, 1985. p. 23-62.

COSTA, L. F. et al. Família e abuso sexual: silêncio e sofrimento entre a denúncia e a intervenção terapêutica. Arquivos Brasileiros de Psicologia, Rio de Janeiro, v. 59, n. 2, p. 245-255, dez. 2007. Disponível em: <http://pepsic.bvsalud.org/pdf/arbp/v59n2/v59n2a13.pdf>. Acesso em: 5 mar. 2014.

COSTA, P. R. S. M.; GROSSI, M. P. Violências de gênero: assassinos/as impiedosos/as ou enlouquecidos/as pela dor do amor? Rev. Estud. Fem., Florianópolis, v. 18, n. 2, p. 620-622, ago. 2010. Disponível em: <http://www.scielo.br/scielo.php?script=sci_arttext\&pid=S0104-026X2010 000200022\&lng=en\&nrm=iso > Acesso em: 30 jan. 2015.

DURKHEIM, É. As regras do método sociológico. Tradução de Pietro Nassetti. São Paulo: Martin Claret, 2001. 
. Da divisão do trabalho social. 2. ed. São Paulo: Martins Fontes, 1999.

GIDDENS, A. Modernidade e Identidade. Tradução de Plínio Dentzien. Rio de Janeiro: Zahar, 2002.

GREGORI, M. F. A desventuras do vitimismo. Estudos Feministas, Rio de Janeiro, ano 1, p. 143-149, $1^{\circ}$ sem. 1993 a.

. Cenas e Queixas. Um Estudo sobre Mulheres, Relações Violentas e a Prática Feminista. Rio de Janeiro/São Paulo: Paz e Terra/ANPOCS, 1993b.

GROSSI, M. P. Novas/velhas violências contra a mulher no Brasil. Estudos Feministas, Rio de Janeiro, ano 2, p. 473-483, 2o sem. 1994. Disponível em: <http://miriamgrossi.paginas.ufsc.br/ files/2012/03/16179-49803-1-PB.pdf>. Acesso em: 30 jan. 2015.

HALL, S. Identidade cultural na pós-modernidade. 11. ed. Tradução de Tomás Tadeu da Silva e Guacira Lopes Louro. Rio de Janeiro: DP\&A, 2007.

IZUMINO, W. P. Resenha: Cenas e queixas. Um estudo sobre mulheres, relaçóes violentas e a prática feminista [Maria Filomena Gregori. São Paulo: Paz e Terra/Anpocs, 1993]. Revista brasileira de Ciências Sociais, São Paulo, v. 8, n. 22, [s. p.], jun. 1993. Disponível em: <http:// anpocs.org.br/portal/publicacoes/rbcs_00_22/rbcs22_resenhas.htm>. Acesso em: 30 jan. 2015.

KOPP, R. O segredo possível na cibercultura. In: ENCONTRO DE NÚCLEOS DE PESQUISA DA INTERCOM, 5., NP 08 - Tecnologias da Informação e da Comunicação, Rio de Janeiro, p. 1-15, 2005. Disponível em: <http://www.intercom.org.br/papers/nacionais/2005/resumos/ R0551-1.pdf>. Acesso em: 5 mar. 2014.

LABRONICI, L. M.; FEGADOLI, D.; CORREA, M. E. C. Significado da violência sexual na manifestação da corporeidade: um estudo fenomenológico. Revista da Escola de Enfermagem da USP. v.44, n. 2, p. 401-406, jun. 2010. Disponível em: http://www.scielo.br/scielo.php?script=sci_ arttext\&pid=S0080-62342010000200023. Acesso em: 9 abr. 2015.

LEANDRO, M. E.; LEANDRO, A. S.; NOGUEIRA, F. A confiança em questão. Raias de confiança, confiança das raias nas sociedades modernas. Sociologia, Revista da Faculdade de Letras da Universidade do Porto, v. XXI, p. 215-232, 2011.

LIMA, D. C; BÜCHELE, F; CLÍMACO, D. de A. Homens, gênero e violência contra a mulher. Saúde \& Sociedade, São Paulo, v. 17, n. 2, p. 1-13, apr./june 2008. Disponível em: <http://www. scielo.br/scielo.php?pid=S0104-12902008000200008\&script=sci_arttext>. Acesso em: 5 mar. 2014. MACHADO, L. Z. Feminismo em movimento. 2. ed. São Paulo: Francis, 2010.

MALDONADO, S. C. Sociologia e Segredo. In: (Org.). Georg Simmel: sentidos, segredos. Tradução de Simome C. Maldonado. Curitiba: Appris, 2011. 
MARZANO-PARISOLI, M. M. Pensar o Corpo. Petrópolis: Vozes, 2004.

MASON, M. J. Vergonha: Reservatório para os segredos na família. In: BLACK, E. I. (Org.). Os segredos na família e na terapia familiar. Porto Alegre: Artes Médicas, p. 40-54, 2002.

MASSELLA, A. B. et al. Durkheim: 150 Anos. Belo Horizonte, MG: Argvmentvm, 2009.

NARVAZ, M. G.; KOLLER, S. H. Mulheres vítimas de violência doméstica: Compreendendo subjetividades assujeitadas. Psico, Porto Alegre, v. 37, n. 1, p. 7-13, jan./abr. 2006. Disponível em: $<$ http://revistaseletronicas.pucrs.br/ojs/index.php/revistapsico/article/view/1405/1105>. Acesso em: 5 mar. 2014.

PERENTE, E. de O.; NASCIMENTO, R. O. do; VIEIRA, L. J. E. de S. Enfrentamento da violência doméstica por um grupo de mulheres após a denúncia. Estudos Feministas, Florianópolis, v. 17, n. 2, p. 1-21, maio/ago. 2009. Disponível em: <http://www.scielo.br/pdf/ref/v17n2/08.pdf>. Acesso em: 5 mar. 2014.

SAFFIOTI, H. I. B. O poder do macho. Sáo Paulo: Moderna, 1987.

SAFFIOTI, H. I. B. A questão da mulher na perspectiva socialista [1967]. Lutas Sociais, São Paulo, n.27, p. 82-100, 20 sem. 2011. Disponível em: <http://www.pucsp.br/neils/downloads/07heleieth-saffioti.pdf $>$. Acesso em: 5 mar. 2014.

Gênero, patriarcado, violência. 2. ed. São Paulo: Editora Fundação Perseu Abramo, 2011. SANTOS, C. M.; IZUMINO, W. P. Violência contra as Mulheres e Violência de Gênero: Notas sobre Estudos Feministas no Brasil. Estudios Interdisciplinarios de América Latina y el Caribe - E.I.A.L., v. 16, n. 1, 2005. Disponível em: <http://www7.tau.ac.il/ojs/index.php/eial/article/ view/482>. Acesso em: 30 jan. 2015.

SARTI, C. A vítima como figura contemporânea. Caderno CRH, Salvador, v. 24, n. 61, p. 1-10, jan./ abr. 2011. Disponível em: <http://www.scielo.br/pdf/ccrh/v24n61/04.pdf>. Acesso em: 5 mar. 2014.

SARTI, C. A.; BARBOSA, R. M; SUAREZ, M. M. Violência e gênero: vítimas demarcadas. Physis, Rio de Janeiro, v. 16, n. 2, p. 167-183, 2006. Disponível em: <http:/www.scielo.br/pdf/ physis/v16n2/v16n2a03.pdf>. Acesso em: 5 mar. 2014.

SIMMEL, G. O segredo. In: MALDONADO, S. C. (Org.). Georg Simmel: sentidos, segredos. Tradução de Simome C. Maldonado. Curitiba: Appris, 2011.

SOARES, B. M. A 'conflitualidade' conjugal e o paradigma da violência contra a mulher. Dilemas, Revista de Estudos de Conflitos e Controle Social, Rio de Janeiro, v. 5, n. 2, p. 191-210, abr./maio/ 
jun. 2012. Disponível em: <http://revistadil.dominiotemporario.com/doc/dilemas-5-2-art1.pdf>. Acesso em: 30 jan. 2015.

STUKER, P. Desigualdade, solidariedade e burocracia: a Lei Maria da Penha e a violência contra a mulher a partir dos clássicos da sociologia. Revista Sociologia Jurídica, n. 15, 2015. Disponível em: <http://www.sociologiajuridica.net.br/numero-15/298-stuker-paola-desigualdadesolidariedade-e-burocracia-a-lei-maria-da-penha-e-a-violencia-contra-a-mulher-a-partir-dosclassicos-da-sociologia>. Acesso em: 9 abr. 2015.

TEIXEIRA, A. B. Nunca você sem mim: homicidas-suicidas nas relações afetivo-conjugais. São Paulo: Annablume, 2009.

TESKE, O. Sociologia: textos e contextos. 2. ed. Canoas: Ulbra, 2005.

WIEVIORKA, M. Pour comprendrer la violence: L'hypothèse du sujet. Sociedade e Estado, Brasília, v. 19, n. 1, p. 21-51, jan./jun. 2004. Disponível em: <http://www.scielo.br/pdf/se/v19n1/ v19n1a03.pdf >. Acesso em: 5 mar. 2014.

Recebido em: 24.03.2014

Aprovado em: 01.03.2015

\section{Crimes and secrets in sexual violence against women: dialogue between Durkheim and Simmel}

\section{Abstract}

This study aims to reflect about the secrets and crimes involving sexual violence against women. This is a literature review on women's experiences, whereas not publicizing the violent act appears as a constant concern among women. From the theoretical framework proposed by Émile Durkheim and Georg Simmel, it was found that this violence is embedded in a social web, whether existential or order of gender hierarchies. In the conception of crime addressed by Durkheim, one can understand that changing values, opposing the states of collective consciousness, is central to that violence against women can be seen as a "criminal act". From Simmel, the secret, as a sociological category, should not be understood as an omission or inertia, but as a way of maintaining social ties. The interactions of individuals extend the possibilities of the social world.

Keywords: Sexual violence. Gender violence. Violence against women. Crime. Secret 